\title{
Multi-active Site Dynamics on a Molecular Cr/Co/Se Cluster Catalyst
}

\author{
Jonathan A. Kephart ${ }^{1}$, Benjamin S. Mitchell ${ }^{1}$, Werner Kaminsky ${ }^{1}$, Alexandra Velian ${ }^{1 *}$ \\ ${ }^{1}$ Department of Chemistry, University of Washington, Seattle, Washington 98195, United States
}

\begin{abstract}
This study provides detailed insights into the interconnected reactivity of the three catalytically active sites of an atomically precise nanocluster $\mathrm{Cr}_{3}(\text { py })_{3} \mathrm{Co}_{6} \mathrm{Se}_{8} \mathrm{~L}_{6}\left(\mathrm{Cr}_{3}(\text { py })_{3}, \mathrm{~L}=\mathrm{Ph}_{2} \mathrm{PNTol}^{-}, \mathrm{Ph}=\right.$ phenyl, Tol $=4$-tolyl). Catalytic and stoichiometric studies into tosyl azide activation and carbodiimide formation enabled the isolation and crystallographic characterization of key metal-nitrenoid catalytic intermediates, including the tris(nitrenoid) cluster $\mathbf{C r}_{3}(\mathrm{NTs})_{3}$, the catalytic resting state $\mathrm{Cr}_{3}(\mathrm{NTs})_{3}\left(\mathrm{CN}^{t} \mathrm{Bu}\right)_{3}$, and the mono(nitrenoid) cluster $\mathrm{Cr}_{3}(\mathrm{NTs})\left(\mathrm{CN}^{t} \mathrm{Bu}\right)_{2}$. Nitrene transfer proceeds via a stepwise mechanism, with the three active sites engaging sequentially to produce carbodiimide. Comparative structural analysis and $\mathrm{CN}^{t} \mathrm{Bu}$ binding studies reveal that the chemical state of neighboring active sites regulates the affinity for substrates of an individual Cr-nitrenoid edge site, intertwining their reactivity through the inorganic support.
\end{abstract}

Understanding and controlling catalytically active sites is the holy grail of nanocatalysis, ${ }^{1-3}$ promising to unlock fundamental insights into their mechanism and facilitate the creation of catalysts designed for specific transformations. The concept of "active sites" was first introduced by Taylor nearly a century ago, ${ }^{4}$ but their identity as low-coordinate surface sites was not experimentally verified until decades later by Ertl. ${ }^{5}$ To date, identifying catalytically active sites experimentally and elucidating their mechanism of action remains exceedingly difficult. While surface characterization techniques can provide atomic level understanding of the identity, location, and even mechanism of active sites in well-defined surfaces, ${ }^{5-8}$ they withhold critical details into bonding and electronic structure that are more easily accessed using the myriad strategies available to molecular chemists.

Atomically precise nanoclusters could enable incorporating molecular precision in the design and mechanistic study of catalytically active sites. ${ }^{2,3}$ Owing to their large surface-to-core ratios, nanoclusters exhibit many potential active sites, making them especially interesting as catalytic platforms. Moreover, minor changes in cluster size ${ }^{6,9}$ morphology, ${ }^{10}$ and composi$\operatorname{tion}^{7,11}$ have a large impact on their reactivity and provide practical approaches to modulate the chemistry of their active sites. For example, edge-doping of $\mathrm{MoS}_{2}$ flakes can tune catalytic efficiency and selectivity in hydrodesulfurization ${ }^{7,11}$ or $\mathrm{CO}_{2}$ reduction. ${ }^{12,13}$ Achieving the potential of nanoclusters, however, requires synthetic innovations to both encode specific catalytic functions at the core and surface, and to produce monodisperse clusters at scale.

A large library of molecular ligand-stabilized transition metal nanoclusters exists, which are solution processable and have discrete chemical compositions. ${ }^{14-17}$ Although the vast majority are not catalytically competent, they contribute important insights into the physicochemical processes that underpin the catalytic interface between active site and support. Select examples include clusters with inorganic $\left[\mathrm{Fe}_{4}\left(\mu_{4}-\mathrm{O}\right)\right]$, $\left[\mathrm{RuCo}_{3}\left(\mu_{3}-\mathrm{O}\right)_{4}\right]$, and $\left[\mathrm{Fe}_{4}\left(\mu_{3}-\mathrm{S}\right)_{4}\right]$ cores, wherein metalbound oxo and nitrenoid substituents are stabilized by coordinative and electronic participation of a polymetallic support, ${ }^{18-20}$ and a series of trinuclear $\left[\mathrm{Fe}_{3}\right]$ and $\left[\mathrm{Cr}_{3}\right]$ clusters in which electronic coupling between the metal centers facilitates cooperative, multi-site reactivity. ${ }^{21,22}$ There are only a few examples of metal-oxide and -chalcogenide clusters that are catalytically active, including $\left[\mathrm{Mo}_{3} \mathrm{~S}_{13}\right]^{2-}$ and $\left[\mathrm{MoFe}_{3}\left(\mu_{3}-\right.\right.$ $\left.\mathrm{S})_{4}\right]$, for hydrogen evolution and hydrazine reduction, ${ }^{23,24}$ respectively, and the cubane-type cluster $\left[\mathrm{Co}_{4}\left(\mu_{3}-\mathrm{O}\right)_{4}\right]$, for catalytic $\mathrm{C}-\mathrm{H}$ activation and water oxidation. ${ }^{25,26}$ In contrast,

a) $\mathrm{MoS}_{2}$

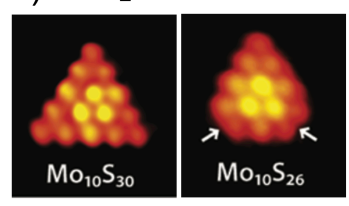

c) $M_{3}$

b) Edge-doped $\mathrm{MoS}_{2}$
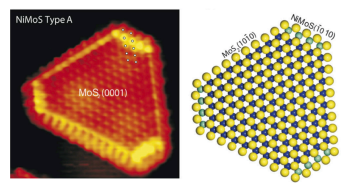

Figure 1. Structural resemblance between a) $\mathrm{MoS}_{2}$, b) edge-doped $\mathrm{MoS}_{2}$, and c) $\mathbf{M}_{3}$ nanoclusters. Images a) and b) are adapted with permission from refs 6 and 7. Copyrights 2010 American Chemical Society and 2007 Elsevier, respectively.

metal clusters, particularly of gold, can catalyze a wide range of reactions ${ }^{27,28}$ However, in part due to scalability challenges, the elucidation of catalytic intermediates remains challenging and relies heavily on computational modeling..$^{29,30}$

Our group introduced a family of molecular clusters, $\mathbf{M}_{3}\left(\mathrm{M}_{3} \mathrm{Co}_{6} \mathrm{Se}_{8} \mathrm{~L}_{6} ; \mathrm{M}=\mathrm{Fe}, \mathrm{Co}, \mathrm{Zn}, \mathrm{Sn} ; \mathrm{L}=\mathrm{Ph}_{2} \mathrm{PNTol}^{-}\right)$, ${ }^{16,31-34}$ that incorporate three chemically addressable edge sites $(\mathrm{M})$ on the surface of a Co/Se cluster core, a construct reminiscent of edgedoped transition metal dichalcogenide nanoflakes (Figure 1). ${ }^{6,7,11}$ Hemilabile edge-support interactions stabilize the three edge sites in protected low-coordinate states,${ }^{31}$ positioning them to function as catalytically active sites and enabling the systematic study of electronic metal-support interactions, ${ }^{35}$ as well as allosteric ${ }^{34}$ and multi-site dynamics on the cluster surface. 
Previously, we discovered that $\mathbf{F e}_{3}$ is an excellent catalyst for converting tosyl azide and tert-butyl isocyanide into carbodiimide, but the role of the Fe edges as the catalytically active sites has not been demonstrated. ${ }^{31}$ It is likely that the reaction proceeds by first activating the organic azide and forming reactive $\mathrm{Fe}(\mathrm{NR})$ species that have thus far eluded observation. We hypothesized that an earlier transition metal might stabilize these high valent metal-nitrenoid intermediates and enable their isolation. Leveraging the synthetic versatility of the $\mathbf{M}_{3}$ construct, a trichromium variant $\mathrm{Cr}_{3}(\mathrm{py})_{3} \mathrm{Co}_{6} \mathrm{Se}_{8} \mathrm{~L}_{6}\left(\mathbf{C r}_{3} \text { (py) }\right)_{3}, 94 \%$ yield; Figure 2) was prepared from the hexalithiated salt $\mathrm{Li}_{6}(\text { py })_{6} \mathrm{C}_{6} \mathrm{Se}_{8} \mathrm{~L}_{6}$ and $\mathrm{CrCl}_{2} \cdot{ }^{31,32}$ Single crystal X-ray diffraction reveals that the 14 $\mathrm{e}^{-}$square pyramidal $\mathrm{Cr}$ (py) edges (Figure 3a) expose open coordination sites for binding substrates at the cluster surface. Like the iron congener, $\mathbf{C r}_{3}(\mathrm{py})_{3}$ is an excellent catalyst for carbodiimide formation (Figure 2). ${ }^{36}$ The conversion of tosyl azide (100 equiv) and tert-butyl isocyanide (165 equiv) to carbodiimide is completed at room temperature within 6 $\mathrm{h}$ of adding the $\mathbf{C r}_{3}(\mathrm{py})_{3}$ cluster $\left(2.5 \%\right.$ loading, $2.8 \mathrm{mM} ; \mathrm{t}_{1 / 2}$ $\sim 44 \mathrm{~min})$, slightly slower than in the case of $\mathbf{F e}_{3}\left(\mathrm{t}_{1 / 2} \sim 35\right.$ $\min$ ).

Each Cr edge of the $\mathbf{C r}_{3}(\mathrm{py})_{3}$ cluster rapidly activates tosyl azide, forming three stable Cr-nitrenoid units at the cluster surface. In the absence of isocyanide, $\mathbf{C r}_{3}(\mathrm{NTs})_{3}(77 \%$ iso-

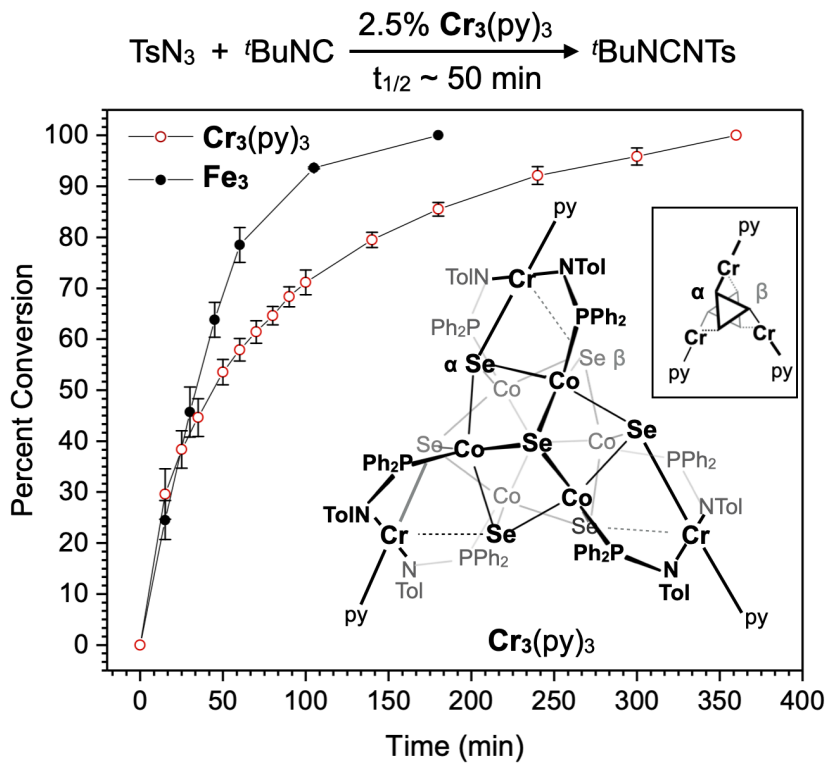

Figure 2. Catalytic carbodiimide formation using $\mathbf{C r}_{3}(\mathrm{py})_{3}$ and $\mathbf{F e}_{3}$ nanoclusters, including kinetic monitoring by ${ }^{1} \mathrm{H}$ NMR spectroscopy. lated yield) is obtained within 15 minutes of mixing $\mathbf{C r}_{3}(\text { py) })_{3}$ with $\mathrm{TsN}_{3}$ (3 equiv; Scheme 1a). In the solid-state, the $\mathrm{Cr}(\mathrm{IV})$ edges adopt a distorted trigonal bipyramidal geometry, with the nitrenoid group oriented equatorially (Figure 3b) ${ }^{37}$ The tosylnitrenoids bind to $\mathrm{Cr}$ by N/O-chelation, ${ }^{38}$ and as a result the $\angle \mathrm{Cr}-\mathrm{N}_{\mathrm{Ts}}-\mathrm{S}$ angles are significantly bent (avg. $96^{\circ}$ ), and the $\mathrm{Cr}-$ $\mathrm{N}_{\mathrm{Ts}}$ double bonds are elongated (avg. $1.82 \AA$ ). ${ }^{39}$ Noteworthy, there is only one other structurally characterized $\mathrm{Cr}(\mathrm{NTs})$ complex in the literature ${ }^{40}$ most undergoing rapid $\mathrm{C}-\mathrm{H}$ activation or $\mathrm{C}-\mathrm{C}$ bond insertion which precludes their observation. ${ }^{41,42}$

Although the three $\mathrm{Cr}(\mathrm{NTs})$ edges have identical first coordination spheres, they are chemically inequivalent due to their $(\alpha, \alpha, \beta)$ orientation on the $\mathrm{Co}_{6} \mathrm{Se}_{8}$ surface. Here $\alpha$ and $\beta$ designate equatorial Se atoms from the top and bottom $\mathrm{Co}_{3} \mathrm{Se}_{4}$ halves of the cubic $\mathrm{Co}_{6} \mathrm{Se}_{8}$ support, respectively, as illustrated in the inset of Figure $2 .{ }^{32}$ Indeed, small variations in the $\mathrm{TsN} / \mathrm{Cr} / \mathrm{Co}_{6} \mathrm{Se} 8$ interactions structurally distinguish the three edge sites, most notable when comparing $\operatorname{Cr}(1)$ with either of the $\operatorname{Cr}(2) \operatorname{or} \operatorname{Cr}(3)$ edges. In solution, the $\mathrm{Cr}(\mathrm{NTs})$ edges remain locked in chemically inequivalent orientations, giving rise to multiple $\mathrm{N}$-tosyl ${ }^{1} \mathrm{H}$ NMR environments. Empirically, we found the $(\alpha, \alpha, \beta)$ orientation of the edge sites to be favored in the $\mathbf{M}_{3}$ nanoclusters, ${ }^{31,32}$ but ligand exchange at the edge sites typically proceeds freely in solution, as is the case for $\operatorname{Cr}_{3}(\text { py })_{3}$. We propose this $(\alpha, \alpha, \beta)$ isomerism reflects the intrinsic preference of the nanocluster to evenly distribute the three electron deficient edge centers on the electron rich $\mathrm{Co}_{6} \mathrm{Se}_{8}$ support, and hypothesize this force guides the formation of $(\alpha, \alpha, \beta)-\mathrm{Cr}_{3}(\mathrm{NTs})_{3}$ as the sole isomer upon reaction of $\mathbf{C r}_{3}(\mathrm{py})_{3}$ with azide.

Stoichiometric studies demonstrate that each of the three edge sites in $\mathbf{C r}_{3}(\mathrm{NTs})_{3}$ can transfer the nitrene group to isocyanide, confirming their viability as catalytically active sites (Scheme 1c). Two equivalents of isocyanide per $\mathrm{Cr}$ center (6 equiv total) are required to complete the nitrene transfer from $\mathbf{C r}_{3}(\mathrm{NTs})_{3}$, forming quantitatively the tris(isocyanide) adduct $\mathbf{C r}_{3}\left(\mathrm{CN}^{t} \mathrm{Bu}\right)_{3}(74 \%$ isolated yield) and carbodiimide $\mathrm{TsNCN}^{t} \mathrm{Bu}$ (3 equiv). In situ ${ }^{1} \mathrm{H}$ NMR monitoring of this reaction reveals that it unfolds via a stepwise mechanism (Figures $4 \mathrm{~b}$ and S15). The edge sites engage sequentially to produce carbodiimide, giving rise in the process to two major observable intermediates, which were isolated independently. The first, $\mathrm{Cr}_{3}(\mathrm{NTs})_{3}\left(\mathrm{CN}^{\prime} \mathrm{Bu}\right)_{3}$, forms upon isocyanide binding at $\mathrm{Cr}_{3}(\mathrm{NTs})_{3}$ and is also the resting state of the nanocluster under catalytic conditions (Figure S16). This species is consumed over the course of $4 \mathrm{~h}$ at room temperature, generating a second, site differentiated intermediate

Scheme 1. Stoichiometric syntheses of catalytically competent intermediates.

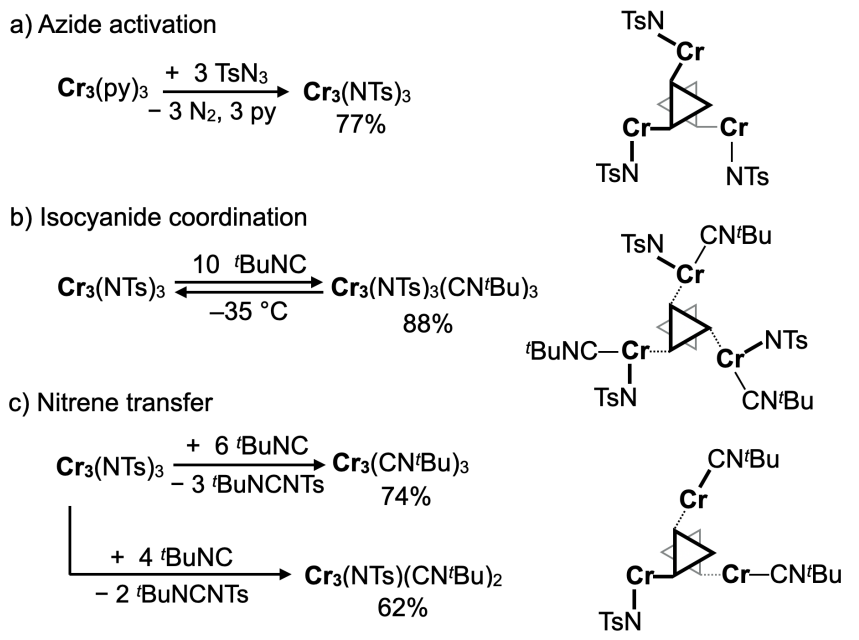




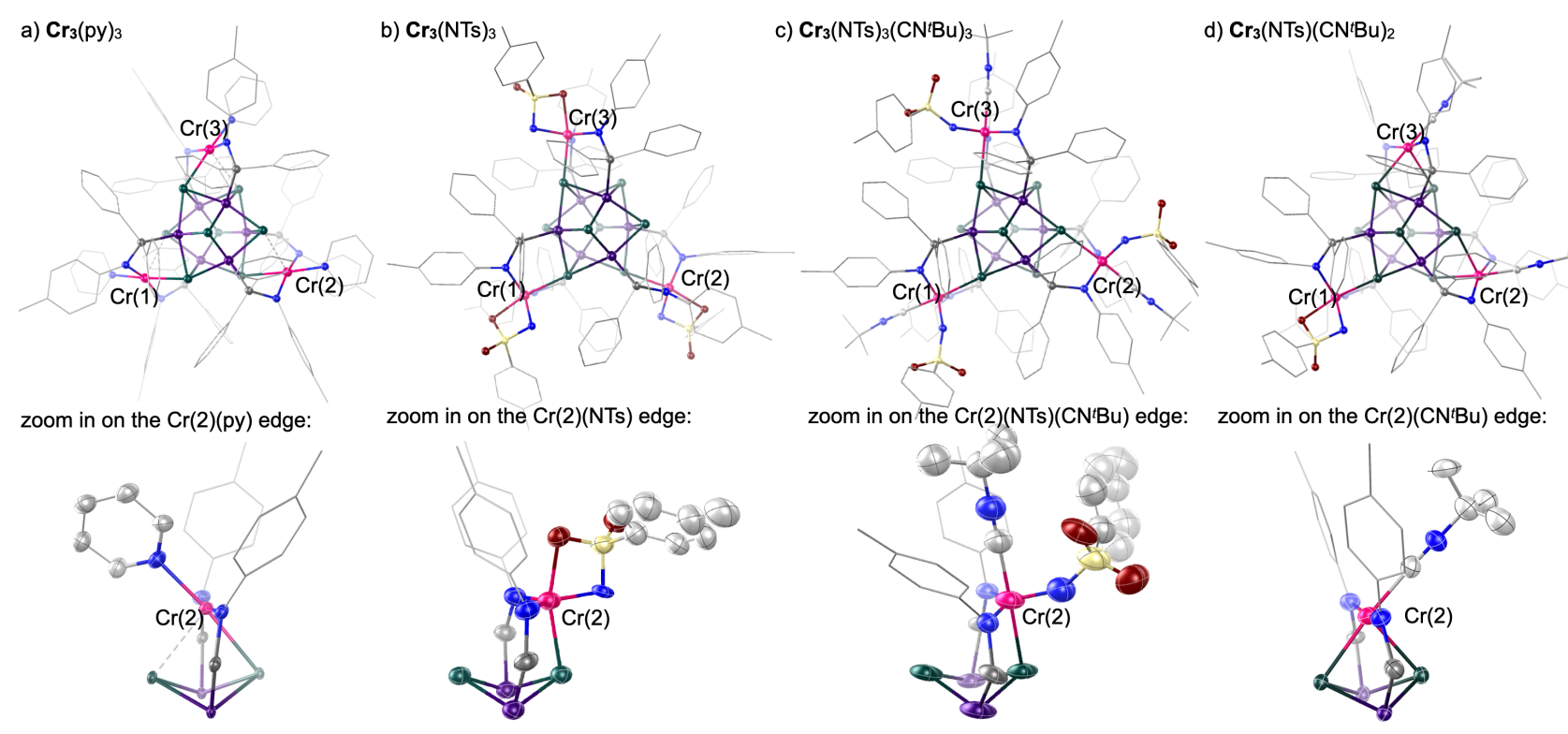

Figure 3. Single crystal X-ray diffraction structures of a) $\mathbf{C r}_{3}(\mathrm{py})_{3}$, b) $\mathbf{C r}_{3}(\mathrm{NTs})_{3}$, c) $\mathbf{C r}_{3}(\mathrm{NTs})_{3}\left(\mathrm{CN}^{t} \mathrm{Bu}\right)_{3}$ and d) $\mathbf{C r}_{3}(\mathrm{NTs})\left(\mathrm{CN}{ }^{t} \mathrm{Bu}\right)_{2}$. Thermal ellipsoids plotted at $50 \%$ probability. $\mathrm{H}$ atoms, disordered ligands and co-crystallized solvents not depicted for clarity.

$\mathrm{Cr}_{3}(\mathrm{NTs})\left(\mathrm{CN}^{t} \mathrm{Bu}\right)_{2}$ and substoichiometric carbodiimide (2 equiv). The last equivalent of carbodiimide is released slowly ( $>48$ h at $\left.60^{\circ} \mathrm{C}\right)$ alongside $\mathrm{Cr}_{3}\left(\mathrm{CN}^{t} \mathrm{Bu}\right)_{3}$.

To independently isolate the first intermediate and unveil the identity of the catalytic resting state, $\mathbf{C r}_{3}(\mathrm{NTs})_{3}$ was treated with $\mathrm{CN}^{t} \mathrm{Bu}\left(10\right.$ equiv) at a temperature sufficiently low to prevent the evolution of carbodiimide $\left(-35^{\circ} \mathrm{C}\right)$. Over the course of 24 $\mathrm{h}$, dark red prismatic crystals of the tris(isocyanide)-tris(nitrenoid) cluster $\mathbf{C r}_{3}(\mathrm{NTs})_{3}\left(\mathrm{CN}^{\prime} \mathrm{Bu}\right)_{3}$ formed quantitatively $(88 \%$ isolated yield, Figure 3c). Single crystal X-ray diffraction uncovers that isocyanide coordination at $\mathbf{C r}_{3}(\mathrm{NTs})_{3}$ strengthens the substrate-edge interactions, but weakens the edge-support ones, trends marked by contracted $\mathrm{Cr}-\mathrm{N}_{\mathrm{Ts}}$ bonds (avg. 1.75 vs 1.82 $\AA$ ) and elongated $\mathrm{Cr}-\mathrm{Se}$ bonds (avg. $2.61 \AA$ vs $2.48 \AA$ ), respectively. The N/O-chelation of the N-tosyl group observed in $\mathrm{Cr}_{3}(\mathrm{NTs})_{3}$ is broken, the $\mathrm{CN}^{t} \mathrm{Bu}$ having displaced the sulfonyl oxygen atom. We propose that the weakening of edge-support bonding interactions and the breaking of the N/O-chelation provide the necessary structural flexibility for the Cr-Se edge contacts to reorganize from $(\alpha, \alpha, \beta)$ in $\mathbf{C r}_{3}(\mathrm{NTs})_{3}$ to the $(\alpha, \alpha, \alpha)$ configuration in $\mathbf{C r}_{3}(\mathrm{NTs})_{3}\left(\mathrm{CN}^{t} \mathrm{Bu}\right)_{3}$ in which all edge sites are identical.

Rather than extruding three equivalents of carbodiimide, $\mathrm{Cr}_{3}(\mathrm{NTs})_{3}\left(\mathrm{CN}^{t} \mathrm{Bu}\right)_{3}$ evolves to a second intermediate that contains a singular $\mathrm{Cr}^{\mathrm{IV}}(\mathrm{NTs})$ edge free of bound isocyanide (Figure S5). Its identity as $\mathrm{Cr}_{3}(\mathrm{NTs})\left(\mathrm{CN}{ }^{t} \mathrm{Bu}\right)_{2}$ was elucidated by independent synthesis (62\% isolated yield) from $\mathbf{C r}_{3}(\mathrm{NTs})_{3}$ and substoichiometric $\mathrm{CN}^{t} \mathrm{Bu}$ (4 equiv; Scheme 1c). Unlike $\mathbf{C r}_{3}(\mathrm{NTs})_{3}\left(\mathrm{CN}^{t} \mathrm{Bu}\right)_{3}$, the mono(nitrenoid) $\mathbf{C r}_{3}(\mathrm{NTs})\left(\mathrm{CN}^{t} \mathrm{Bu}\right)_{2}$ is indefinitely stable at room temperature, evidence of the high affinity for isocyanide of the two $\mathrm{Cr}$ (II) sites which do not release isocyanide that would otherwise strip the nitrene off the Cr(NTs) edge. Despite this high affinity, the $\mathrm{Cr}-\mathrm{CN}^{t} \mathrm{Bu}$ bonding interactions in $\mathbf{C r}_{3}(\mathrm{NTs})\left(\mathrm{CN}^{t} \mathrm{Bu}\right)_{2}$ are among the longest ever reported (avg. $2.08 \AA$ ), ${ }^{43}$ and the $\mathrm{CN}$ stretching frequency $\left(v_{\mathrm{CN}}=2196 \mathrm{~cm}^{-1}\right)$ is extremely blue-shifted, a mark of the electron deficiency of these $\mathrm{Cr}$ centers which do not engage in $\pi$-backbonding.

Comparing the $\mathrm{Cr}(\mathrm{NTs})$ sites in $\mathbf{C r}_{3}(\mathrm{NTs})_{3}$ and $\mathrm{Cr}_{3}(\mathrm{NTs})\left(\mathrm{CN}^{t} \mathrm{Bu}\right)_{2}$ we discovered that the chemical state of the neighboring active sites on the cluster impact its structure and reactivity. Although of identical coordination environment to those in $\mathrm{Cr}_{3}(\mathrm{NTs})_{3}$, the $\mathrm{Cr}(\mathrm{NTs})$ edge in $\mathbf{C r}_{3}(\mathrm{NTs})\left(\mathrm{CN}^{t} \mathrm{Bu}\right)_{2}$ features a strengthened $\mathrm{Cr}-\mathrm{Se}$ interaction $(2.444(2)$ vs $2.48 \mathrm{avg}$. $\AA$ ), and an elongated $\mathrm{Cr}-\mathrm{N}_{\mathrm{Ts}}$ bond (1.862(9) vs $1.82 \mathrm{avg}$. $\AA$; Figure $3 \mathrm{~d}$ ) in the solid state. To probe if the strengthened edge-support interaction distinguishes the reactivity of the $\mathrm{Cr}(\mathrm{NTs})$ edge, the isocyanide binding affinities of $\mathbf{C r}_{3}(\mathrm{NTs})_{3}$ and $\mathbf{C r}_{3}(\mathrm{NTs})\left(\mathrm{CN}^{t} \mathrm{Bu}\right)_{2}$ were compared. Using ${ }^{1} \mathrm{H}$ NMR spectroscopy, the binding constant for isocyanide at the $\mathbf{C r}_{3}(\mathrm{NTs})_{3}$ cluster to produce $\mathrm{Cr}_{3}(\mathrm{NTs})_{3}\left(\mathrm{CN}^{\prime} \mathrm{Bu}\right)_{1-3}$ adducts at room temperature is estimated to be $44(7) \mathrm{M}^{-1}$, whereas there is no spectroscopic evidence of any isocyanide binding at the $\mathrm{Cr}(\mathrm{NTs})$ site in $\mathrm{Cr}_{3}(\mathrm{NTs})\left(\mathrm{CN}^{t} \mathrm{Bu}\right)_{2}$ under identical conditions (see SI, Section S4). We propose that structural differentiation with $\mathrm{Cr}^{\mathrm{II}}\left(\mathrm{CN}^{t} \mathrm{Bu}\right)$ edge sites slows nitrene transfer kinetics at this third edge site, distinguishing its reactivity from that of the first $\mathrm{Cr}(\mathrm{NTs})$ edge. The strengthened edge-support interactions in $\mathrm{Cr}_{3}(\mathrm{NTs})\left(\mathrm{CN}^{t} \mathrm{Bu}\right)_{2}$ are associated with a reorganization back to $(\alpha, \alpha, \beta)$ symmetry in the solid state. This rearrangement reinforces the hypothesis that $\alpha / \beta$ isomerism enables the $\mathrm{C}_{6} \mathrm{Se}_{8}$ support to reversibly distribute electron density via structural changes in response to substrate binding events at the active sites. 

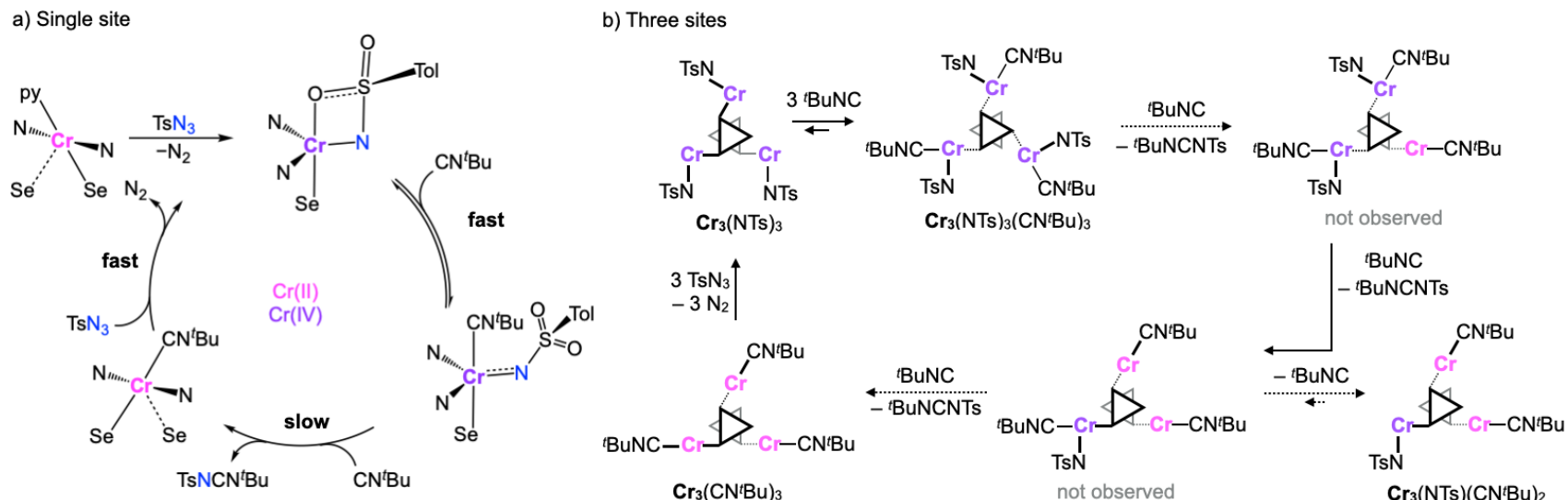

Figure 4. Proposed catalytic cycle for carbodiimide formation at a) an isolated $\mathrm{Cr}$ edge site, and b) considering all three $\mathrm{Cr}$ edge sites (under stoichiometric conditions).

Informed by the catalytic and stoichiometric reactivity of the $\mathbf{C} \mathbf{r}_{3}$ nanoclusters, a catalytic cycle is proposed (Figure 4). At a single edge, the cycle begins with a $\mathrm{Cr}^{\mathrm{II}} \mathrm{L}^{\prime}\left(\mathrm{L}^{\prime}=\right.$ py, $\left.\mathrm{CN}^{t} \mathrm{Bu}\right)$ site that quickly activates tosyl azide, producing a $\mathrm{Cr}^{\mathrm{IV}}(\mathrm{NTs})$ species. Isocyanide binding to $\mathrm{Cr}^{\mathrm{IV}}(\mathrm{NTs})$ disrupts the N/O-chelation of the $\mathrm{N}$-tosyl group, and generates the catalytic resting state $\mathrm{Cr}^{\mathrm{IV}}(\mathrm{NTs})\left(\mathrm{CN}^{t} \mathrm{Bu}\right)$. Although both coupling substrates are already bound at the $\mathrm{Cr}^{\mathrm{IV}}(\mathrm{NTs})\left(\mathrm{CN}^{t} \mathrm{Bu}\right)$ edge, an additional equivalent of isocyanide is required for the reductive elimination to proceed. Extrusion of carbodiimide is the rate determining step and regenerates the $\mathrm{Cr}^{\mathrm{II}}\left(\mathrm{CN}^{t} \mathrm{Bu}\right)$ site, which is ready to reengage with azide. Figure $4 \mathrm{~b}$ details a proposed cycle that considers the ensemble, multi-site dynamics on the surface of the nanocluster. Subtle electronic and structural differences distinguish the individual $\mathrm{Cr}$ edge sites of the nanocluster, leading to interdependent and sequential reactivity. We propose that as the $\mathrm{Cr}^{\mathrm{II}}\left(\mathrm{CN}^{t} \mathrm{Bu}\right)$ edges are regenerated on the nanocluster, they have a stabilizing effect on the neighboring $\mathrm{Cr}^{\mathrm{IV}}(\mathrm{NTs})$ edges, deactivating them towards isocyanide binding and, consequently, nitrene transfer. Throughout the catalytic cycle, the inorganic $\mathrm{Co} / \mathrm{Se}$ support is structurally responsive to substrate activation and transfer with hemilabile $\mathrm{Cr}-\mathrm{Se}$ interactions that enable facile transitions between $\kappa^{3}$ and $\kappa^{4}$ binding and accommodate the $\mathrm{Cr}$ edge sites in diverse configurations.

The dichotomy between the stability of the $\mathrm{Cr}(\mathrm{NTs})$ edges in the $\mathbf{C r} 3$ clusters towards isolation and their propensity to accomplish group transfer catalytically is unusual and uniquely positions $\mathbf{C r}_{3}$ for mechanistic investigations. In fact, nitrenoid-bound transition metal-chalcogenide clusters are exceptionally rare. Only two others having been previously reported, the cubanetype $\mathrm{Fe}_{4} \mathrm{~S}_{4}(\mathrm{NAr})$ and $\mathrm{Mo}_{4} \mathrm{~S}_{4}(\mathrm{NAr})_{4}$ clusters, ${ }^{18,44}$ but neither have been shown to be catalytically competent or active towards stoichiometric group transfer chemistry. $\mathbf{C r}_{3}$ is not only a functional model for heterogeneous single-atom group transfer catalysis, but also a powerful platform to study the dynamics of nearest neighbor active sites in heterogenous catalysts. While the push-pull dynamic between the substrate/edge/support is central to completing a catalytic cycle at an isolated Cr edge site, a domino effect wherein electronic changes propagate through the $\mathrm{Co}_{6} \mathrm{Se}_{8}$ support informs and modulates the reactivity of the neighboring active sites. Overall, this study sheds light on the mechanism of nitrene transfer at the surface of a well-defined nanocluster catalyst bearing three operational active sites, achieving a level of detail that is unprecedented in nanocluster catalysis.

\section{ASSOCIATED CONTENT}

Supporting Information. Experimental procedures, characterization data including cif files are available online.

\section{AUTHOR INFORMATION}

\section{Corresponding Author}

Alexandra Velian - Department of Chemistry, University of Washington, Seattle, Washington 98195, United States; ORCID: 0000-0002-6782-7139; Email: avelian@uw.edu

\section{Authors}

Jonathan A. Kephart - Department of Chemistry, University of Washington, Seattle, Washington 98195, United States; ORCID: 0000-0003-4608-1160

Benjamin S. Mitchell - Department of Chemistry, University of Washington, Seattle, Washington 98195, United States; ORCID: 0000-0001-6586-2237

Werner Kaminsky - Department of Chemistry, University of Washington, Seattle, Washington 98195, United States; ORCID: $\underline{0000-0002-9100-4909}$ 


\section{ACKNOWLEDGMENT}

This work was supported by the National Science Foundation (NSF) through a Faculty Early Career Development Program Award (1944843) and by the Research Corporation for Science Advancement through a Cottrell Scholars Award. The X-ray crystallography facility was funded through NSF Grant 0840520. B.S.M. is grateful for support from the NSF Graduate Research Fellowship Program.

\section{REFERENCES}

(1) K. Nørskov, J.; Bligaard, T.; Hvolbæk, B.; Abild-Pedersen, F.; Chorkendorff, I.; H. Christensen, C. The Nature of the Active Site in Heterogeneous Metal Catalysis. Chem. Soc. Rev. 2008, 37 (10), 2163-2171. https://doi.org/10.1039/B800260F.

(2) Tyo, E. C.; Vajda, S. Catalysis by Clusters with Precise Numbers of Atoms. Nat. Nanotechnol. 2015, 10 (7), 577-588. https://doi.org/10.1038/nnano.2015.140.

(3) Du, X.; Jin, R. Atomically Precise Metal Nanoclusters for Catalysis. ACS Nano 2019. https://doi.org/10.1021/acsnano.9b04533.

(4) Taylor, H. S.; Armstrong, E. F. A Theory of the Catalytic Surface. Proc. R. Soc. Lond. Ser. Contain. Pap. Math. Phys. Character 1925, 108 (745), 105-111. https://doi.org/10.1098/rspa.1925.0061.

(5) Zambelli, T.; Wintterlin, J.; Trost, J.; Ertl, G. Identification of the "Active Sites" of a Surface-Catalyzed Reaction. Science 1996. https://doi.org/10.1126/science.273.5282.1688.

(6) Tuxen, A.; Kibsgaard, J.; Gøbel, H.; Lægsgaard, E.; Topsøe, H.; Lauritsen, J. V.; Besenbacher, F. Size Threshold in the Dibenzothiophene Adsorption on $\mathrm{MoS}_{2}$ Nanoclusters. ACS Nano 2010, 4 (8), 4677-4682. https://doi.org/10.1021/nn1011013.

(7) Lauritsen, J.; Kibsgaard, J.; Olesen, G.; Moses, P.; Hinnemann, B.; Helveg, S.; Norskov, J.; Clausen, B.; Topsoe, H.; Lagsgaard, E. Location and Coordination of Promoter Atoms in Co- and Ni-Promoted MoS2-Based Hydrotreating Catalysts. J. Catal. 2007, 249 (2), $220-233$. https://doi.org/10.1016/j.jcat.2007.04.013.

(8) Jaramillo, T. F.; Jorgensen, K. P.; Bonde, J.; Nielsen, J. H.; Horch, S.; Chorkendorff, I. Identification of Active Edge Sites for Electrochemical H2 Evolution from MoS2 Nanocatalysts. Science 2007, 317 (5834), 100-102. https://doi.org/10.1126/science.1141483.

(9) Xu, Z.; Xiao, F.-S.; Purnell, S. K.; Alexeev, O.; Kawi, S.; Deutsch, S. E.; Gates, B. C. Size-Dependent Catalytic Activity of Supported Metal Clusters. Nature 1994, 372 (6504), 346-348. https://doi.org/10.1038/372346a0.

(10) Influence of Atomic-Level Morphology on Catalysis: The Case of Sphere and Rod-Like Gold Nanoclusters for CO2 Electroreduction I ACS Catalysis https://pubs.acs.org/doi/abstract/10.1021/acscatal.8b00365 (accessed 2022 -01 -04).

(11) Kibsgaard, J.; Tuxen, A.; Knudsen, K. G.; Brorson, M.; Topsøe, H.; Lægsgaard, E.; Lauritsen, J. V.; Besenbacher, F. Comparative AtomicScale Analysis of Promotional Effects by Late 3d-Transition Metals in MoS2 Hydrotreating Catalysts. J. Catal. 2010, 272 (2), 195-203. https://doi.org/10.1016/j.jcat.2010.03.018.

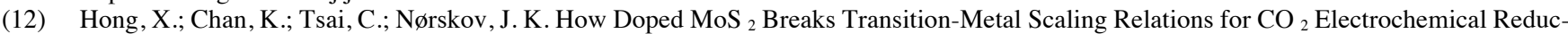
tion. ACS Catal. 2016, 6 (7), 4428-4437. https://doi.org/10.1021/acscatal.6b00619.

(13) Abbasi, P.; Asadi, M.; Liu, C.; Sharifi-Asl, S.; Sayahpour, B.; Behranginia, A.; Zapol, P.; Shahbazian-Yassar, R.; Curtiss, L. A.; SalehiKhojin, A. Tailoring the Edge Structure of Molybdenum Disulfide toward Electrocatalytic Reduction of Carbon Dioxide. ACS Nano 2017, 11 (1), 453-460. https://doi.org/10.1021/acsnano.6b06392.

(14) Doud, E. A.; Voevodin, A.; Hochuli, T. J.; Champsaur, A. M.; Nuckolls, C.; Roy, X. Superatoms in Materials Science. Nat. Rev. Mater. 2020, 5 (5), 371-387. https://doi.org/10.1038/s41578-019-0175-3.

(15) Yan, J.; Teo, B. K.; Zheng, N. Surface Chemistry of Atomically Precise Coinage-Metal Nanoclusters: From Structural Control to Surface Reactivity and Catalysis. Acc. Chem.Res. 2018, 51 (12), 3084-3093. https://doi.org/10.1021/acs.accounts.8b00371.

(16) Kephart, J. A.; Boggiano, A. C.; Kaminsky, W.; Velian, A. Inorganic Clusters as Metalloligands: Ligand Effects on the Synthesis and Properties of Ternary Nanopropeller Clusters. Dalton Trans. 2020, 49 (45), 16464-16473. https://doi.org/10.1039/D0DT02416C.

(17) Chakraborty, S.; Petel, B. E.; Schreiber, E.; Matson, E. M. Atomically Precise Vanadium-Oxide Clusters. Nanoscale Adv. 2021, 3 (5), 12931318. https://doi.org/10.1039/D0NA00877J.

(18) Sridharan, A.; Brown, A. C.; Suess, D. L. M. A Terminal Imido Complex of an Iron-Sulfur Cluster. Angew. Chem. Int. Ed. 2021, 60 (23), 12802-12806. https://doi.org/10.1002/anie.202102603.

(19) Reed, C. J.; Agapie, T. A Terminal Fe III -Oxo in a Tetranuclear Cluster: Effects of Distal Metal Centers on Structure and Reactivity. J. Am. Chem. Soc. 2019, 141 (24), 9479-9484. https://doi.org/10.1021/jacs.9b03157.

(20) Amtawong, J.; Balcells, D.; Wilcoxen, J.; Handford, R. C.; Biggins, N.; Nguyen, A. I.; Britt, R. D.; Tilley, T. D. Isolation and Study of Ruthenium-Cobalt Oxo Cubanes Bearing a High-Valent, Terminal Ru v _Oxo with Significant Oxyl Radical Character. J. Am. Chem. Soc. 2019, 141 (50), 19859-19869. https://doi.org/10.1021/jacs.9b10320.

(21) Bartholomew, A. K.; Juda, C. E.; Nessralla, J. N.; Lin, B.; Wang, S. G.; Chen, Y.; Betley, T. A. Ligand-Based Control of Single-Site vs. Multi-Site Reactivity by a Trichromium Cluster. Angew. Chem. Int. Ed.2019, 58 (17), 5687-5691. https://doi.org/10.1002/anie.201901599.

(22) Powers, T. M.; Betley, T. A. Testing the Polynuclear Hypothesis: Multielectron Reduction of Small Molecules by Triiron Reaction Sites. J. Am. Chem. Soc. 2013, 135 (33), 12289-12296. https://doi.org/10.1021/ja405057n.

(23) Kibsgaard, J.; Jaramillo, T. F.; Besenbacher, F. Building an Appropriate Active-Site Motif into a Hydrogen-Evolution Catalyst with Thiomolybdate [Mo3S13]2- Clusters. Nat. Chem. 2014, 6 (3), 248-253. https://doi.org/10.1038/nchem.1853.

(24) Coucouvanis, D.; Mosier, P. E.; Demadis, K. D.; Patton, S.; Malinak, S. M.; Kim, C. G.; Tyson, M. A. The Catalytic Reduction of Hydrazine to Ammonia by the MoFe3S4 Cubanes and Implications Regarding the Function of Nitrogenase. Evidence for Direct Involvement of the Molybdenum Atom in Substrate Reduction. J. Am. Chem. Soc. 1993, 115 (25), 12193-12194. https://doi.org/10.1021/ja00078a079.

(25) Amtawong, J.; Skjelstad, B. B.; Balcells, D.; Tilley, T. D. Concerted Proton-Electron Transfer Reactivity at a Multimetallic Co ${ }_{4} \mathrm{O}_{4} \mathrm{Cubane}$ Cluster. Inorg. Chem. 2020, 59 (20), 15553-15560. https://doi.org/10.1021/acs.inorgchem.0c02625.

(26) Song, F.; Moré, R.; Schilling, M.; Smolentsev, G.; Azzaroli, N.; Fox, T.; Luber, S.; Patzke, G. R. $\left\{\mathrm{Co}_{4} \mathrm{O}_{4}\right\}$ and $\left\{\mathrm{Co}_{x} \mathrm{Ni}_{4-x} \mathrm{O}_{4}\right\}$ Cubane Water Oxidation Catalysts as Surface Cut-Outs of Cobalt Oxides. J. Am. Chem. Soc. 2017, 139 (40), 14198-14208. https://doi.org/10.1021/jacs.7b07361.

(27) Luo, Z.; Castleman, A. W.; Khanna, S. N. Reactivity of Metal Clusters. Chem. Rev. 2016, 116 (23), 14456-14492. https://doi.org/10.1021/acs.chemrev.6b00230. 
(28) Jin, R.; Li, G.; Sharma, S.; Li, Y.; Du, X. Toward Active-Site Tailoring in Heterogeneous Catalysis by Atomically Precise Metal Nanoclusters with Crystallographic Structures. Chem. Rev. 2021, 121 (2), 567-648. https://doi.org/10.1021/acs.chemrev.0c00495.

(29) Luo, Z.; Khanna, S. N. Metal Cluster Catalysis. In Metal Clusters and Their Reactivity; Springer Singapore: Singapore, 2020; pp 215-239. https://doi.org/10.1007/978-981-15-9704-6_13.

(30) Ren, Y.; Yang, Y.; Zhao, Y .-X.; He, S.-G. Conversion of Methane with Oxygen to Produce Hydrogen Catalyzed by Triatomic Rh ${ }_{3}{ }^{-}$Cluster Anion. JACS Au 2021, jacsau.1c00469. https://doi.org/10.1021/jacsau.1c00469.

(31) Kephart, J. A.; Mitchell, B. S.; Chirila, A.; Anderton, K. J.; Rogers, D.; Kaminsky, W.; Velian, A. Atomically Defined Nano-Propeller Fe 3 $\mathrm{Co}_{6} \mathrm{Se}_{8}\left(\mathrm{Ph}_{2} \mathrm{PNTol}_{6}\right.$ : Functional Model for the Electronic Metal-Support Interaction Effect, and High Catalytic Activity for Carbodiimide Formation. J. Am. Chem. Soc. 2019, 141 (50), 19605-19610. https://doi.org/10.1021/jacs.9b12473.

(32) Kephart, J. A.; Romero, C. G.; Tseng, C.-C.; Anderton, K. J.; Yankowitz, M.; Kaminsky, W.; Velian, A. Hierarchical Nanosheets Built from Superatomic Clusters: Properties, Exfoliation and Single-Crystal-to-Single-Crystal Intercalation. Chem. Sci. 2020, 11 (39), 10744-10751. https://doi.org/10.1039/D0SC03506H.

(33) Mitchell, B. S.; Kaminsky, W.; Velian, A. Tuning the Electronic Structure of Atomically Precise Sn/Co/Se Nanoclusters via Redox Matching of Tin(IV) Surface Sites. Inorg. Chem. 2021, 60 (9), 6135-6139. https://doi.org/10.1021/acs.inorgchem.1c00313.

(34) Mitchell, B. S.; Krajewski, S. M.; Kephart, J. A.; Rogers, D.; Kaminsky, W.; Velian, A. Redox-Switchable Allosteric Effects in Molecular Clusters. JACS Au 2021. https://doi.org/10.1021/jacsau.1c00491.

(35) Campbell, C. T. Catalyst-Support Interactions: Electronic Perturbations. Nat. Chem. 2012, 4 (8), 597-598. https://doi.org/10.1038/nchem.1412.

(36) Yousif, M.; Tjapkes, D. J.; Lord, R. L.; Groysman, S. Catalytic Formation of Asymmetric Carbodiimides at Mononuclear Chromium(II/IV) Bis(Alkoxide) Complexes. Organometallics 2015, 34 (20), 5119-5128. https://doi.org/10.1021/acs.organomet.5b00703.

(37) Dong, Y.; Clarke, R. M.; Zheng, S.-L.; Betley, T. A. Synthesis and Electronic Structure Studies of a Cr-Imido Redox Series. Chem. Commun. 2020, 56 (21), 3163-3166. https://doi.org/10.1039/D0CC00108B.

(38) Laskowski, C. A.; Hillhouse, G. L. Group-Transfer Reactions of Ni(II)-Ni(II) Bridging Imido Complexes. Catalytic Formation of Carbodiimides and Isocyanates via Nitrene Transfer from Organoazides. Organometallics 2009, 28 (20), 6114-6120. https://doi.org/10.1021/om900783u.

(39) A Search for All Cr...N Double Bond Lengths in the Cambridge Structural Database (Updated November 2020) Yielded 153 Hits between 1.55 and $1.874 \AA$ (Mean 1.65(3) Å). A Similar Search for Cr...N Single Bond Lengths Yielded 3786 Hits between 1.763 and $2.443 \AA$ (Mean 2.06(9) $\AA$ ).

(40) Zdilla, M. J.; Abu-Omar, M. M. Mechanism of Catalytic Aziridination with Manganese Corrole: The Often Postulated High-Valent Mn(V) Imido Is Not the Group Transfer Reagent. J. Am. Chem. Soc. 2006, 128 (51), 16971-16979. https://doi.org/10.1021/ja0665489.

(41) Zhou, W.; Patrick, B. O.; Smith, K. M. Influence of Redox Non-Innocent Phenylenediamido Ligands on Chromium Imido Hydrogen-Atom Abstraction Reactivity. Chem Commun 2014, 50 (69), 9958-9960. https://doi.org/10.1039/C4CC04545A.

(42) Heins, S. P.; Morris, W. D.; Wolczanski, P. T.; Lobkovsky, E. B.; Cundari, T. R. Nitrene Insertion into C C and C Diimine Ligands Ligated to Chromium and Iron. Angew. Chem.Int.Ed.2015, 54 (48), 14407-14411. https://doi.org/10.1002/anie.201507463.

(43) A Search for All Cr...C(CNtBu) Bond Lengths in the Cambridge Structural Database (Updated November 2020) Yielded 53 Hits between 1.87 and $2.068 \AA$ (Mean 1.97(3) $\AA$ ).

(44) Hogarth, G.; Richards, I. Regioselective and Reversible Carbon-Nitrogen Bond Formation: Synthesis, Structure and Reactivity of UreatoBridged Complexes $\left[\mathrm{Mo}_{2}(\mathrm{NAr})_{2}(\mu-\mathrm{X})\{\mu\right.$ - $\left.\mathrm{ArNC}(\mathrm{O}) \mathrm{NAr}\}\left(\mathrm{S}_{2} \mathrm{CNR}_{2}\right)_{2}\right](\mathrm{Ar}=\mathrm{Ph}, \mathrm{p}-\mathrm{Tol} ; \mathrm{X}=\mathrm{S}, \mathrm{NAr} ; \mathrm{R}=\mathrm{Me}$, Et, $\mathrm{Pr})$. Dalton Trans 2005, No. 4, 760-773. https://doi.org/10.1039/B417234P. 